\title{
LOWER WAIST-TO-HIP, WAIST-TO-STATURE, AND Waist-to-Bust Ratios Predict Higher RaNKINGS OF Plus-Size Models in a Naturalistic Condition
}

\author{
Toe Aung ${ }^{1} \&$ Leah Williams ${ }^{2}$ \\ 1Department of Anthropology, The Pennsylvania State University, Pennsylvania, USA. \\ 2Independent Researcher, State College, Pennsylvania, USA.
}

txa96@psu.edu

\begin{abstract}
Previous research suggests that waist-to-hip ratio (WHR), waist-to-stature ratio (WSR), and waist-to-bust ratio (WBR) serve as cues of health and fertility in women, influencing the viewers' perception of attractiveness. However, it is unclear to what extent these findings can be applied to the perception of female attractiveness in a naturalistic condition or in women with a higher body mass index. In this study, we tested whether lower WHR, WSR, and WBR increased the perceived attractiveness of plus-size models in a naturalistic condition. The WHR, WSR, and WBR were computed via biometric data (height, bust, waist, and hip measurements) of 49 U.S. plus-size models who have been listed on ranker.com. The photographs of these models have been viewed 2.60 million times and voted 146,000 times. The perception of attractiveness was operationalized as rankings, generated from the relative number of upvotes and downvotes from site visitors. Spearman correlations showed that lower WHR, WSR, and WBR were all positively correlated with higher rankings. In a subsequent ordinal logistic regression, only WSR and WBR remained as significant predictors of rankings. The principal component regression also revealed that the latent body component of WHR, $W S R$, and WBR predicted rankings of the models. These findings cannot be accounted by the models' general popularity or their anthropometric measures being similar to other types of models' (e.g., fashion, glamor, playboy, and adult film models). Our findings suggest that smaller WHR, WSR, and WBR influence the perception of female attractiveness in a naturalistic condition, even among plus-size models.
\end{abstract}

Keywords: Waist-to-Hip-Ratio, Waist-to-Stature-Ratio, Waist-to-Bust-Ratio, Plus-Size Models, Anthropometric Measures. 


\section{INTRODUCTION}

\section{Anthropometric Measures as Cues of Health and Fertility in Females}

Evolutionary psychologists argue that our preferences for physical attractiveness do not merely suggest arbitrary standards set by cultures but reflect specific psychological mechanisms that helped us solve a specific adaptive problem (Buss, 1989; Gangestad \& Buss, 1993; Rhodes, 2006; Singh, Dixson, Jessop, Morgan, \& Dixson, 2010). An adaptive problem refers to the ancestral conditions that have recurrent impacts on our ancestral humans' survival or reproduction (Cosmides \& Tooby, 1995). One of the adaptive problems that our human ancestors must solve is to find, attract, and successfully reproduce with a fertile mate (Lewis, Al-Shawaf, Conroy-Beam, Asao, \& Buss, 2017; Cornelissen, Hancock, Kiviniemi, George, \& Tovée, 2009). The genes of our ancestors who successfully solved the problem associated with finding, attracting, and reproducing with fertile mates were more likely to spread their genes than those who did not; hence, evolutionary psychologists argue that humans would be designed to possess specific sensory, physiological, and psychological mechanisms that detect cues of health and fertility in potential partners (Lewis et al., 2017).

Over the years, several anthropometric measures have been proposed by evolutionary psychologists as cues of health and fertility in females. These anthropometric measures include, but are not limited to, waist-to-hip ratio (WHR), body mass index (BMI), waist-to-bust ratio (WBR), and waist-to-stature ratio (WSR) (Fisher \& Voracek, 2005; Kościński, 2014; Lassek \& Gaulin, 2016; Voracek \& Fisher, 2006). Although evolutionary psychology studies are oftentimes concerned with functional explanations (e.g., Andrews, Lukaszewski, Simmons, \& Bleske-Rechek, 2017; Jasien'ska, Ziomkiewicz, Ellison, Lipson, \& Thune, 2004; Singh, 1993), a more multifaceted understanding of why certain anthropometric measures determine female attractiveness in humans can be benefited by Tinbergen's four questions (Tinbergen, 1963).

\section{Tinbergen's Four Questions}

Using WHR, WSR, and WBR as examples, we have highlighted why these measures are important for female physical attractiveness via Tinbergen's four questions: mechanism, ontogeny, adaptive function, and evolution (Table 1). WHR, WSR, and WBR are influenced by physiological mechanisms, such as estradiol concentrations (Alison et al., 2005; Mondragón-Ceballos, García Granados, Cerda-Molina, Chavira-Ramírez, \& Hernández-López, 2015; Pedersen, Kristensen, Hermann, Katzenellenbogen, \& Richelsen, 2004) and gene polymorphism (Heid et al., 2010; Schuit et al., 2004). These measures also change across lifespan. In women, WHR, WSR, and WBR become lower as women go through puberty and increase as a function of women's age and parity (Andrews et al., 2017; Butoskaya et al., 2017; Park et al., 2018; Shimokata, Andres, Coon, Elahi, Muller, \& Tobin, 1989). Thus, changes in waist, height, and bust in women signal their age, and parity to both men and women. Mate selection theory argues that men would prefer cues in women that signal health and fertility, and women would also prefer cues that men find attractive, which would allow them to judge their own mate values, with respect to others (Tovée \& Cornelissen, 2001). Thus, lower WHR, WSR, and WBR would be attractive to men and ideal for women. 
The influence of lower WHR, WSR, and WBR on female attractiveness would be incomplete without considering our phylogenetic history and the adaptive problems our hominin ancestors had to solve: the efficient bipedal locomotion and the production of a large-brain offspring. The adaptation to bipedalism possibly led to the development of waist and hip in humans (Schultz, 1969), and the production of a large-brain offspring produced a physical feature that stores a large amount of body fat in women's waist, hips, and breasts (Dufour \& Slather, 2002; Pond, 1997). In particular, lower WHRs in ancestral women could have been important for providing essential fatty acids and energy for the development of a large-brain infant (see Lassek \& Gaulin, 2006). During the later period of our hominin lineage, the selection pressure on pelvis size for infants with larger brains could have been in direct conflict with the earlier selection pressure on effective bipedal locomotion (Wittman \& Wall, 2007). Gluckman and Hanson (2006) suggested that female height must have been under positive selection in the hominin line since a certain level of skeletal height in females must correlate with the growth of pelvis development (Ellison, 2009), making the pelvis sufficient for the passage of a largerbrained infant, without a huge cost to the efficient bipedal locomotion. Hence, a lower WHR, WSR, and WBR in ancestral women could have been signs of both sexual maturity and a low parity, with a high potential to birth and nurture a larger-brained infant. Our preferences for a lower WHR, WSR, and WBR in females possibly reflect potential solutions to the adaptive problems our ancestors faced.

Table 1: Tinbergen's Four Questions on Waist-to-hip ratio (WHR), Waist-to-stature ratio (WSR) and Waist-to-bust ratio (WBR) in Women

\begin{tabular}{|c|c|c|}
\hline Proximate Questions & Mechanism & Ontogeny \\
\hline $\begin{array}{l}\text {-What physiological mechanisms } \\
\text { influence WHR, WSR, and } \\
\text { WBR? } \\
\text {-How do WHR, WSR, and WBR } \\
\text { change across women's lifespan? }\end{array}$ & $\begin{array}{l}\text {-Hormonal levels, such as estradiol concentrations regulate fat } \\
\text { accumulation in waist, hip, bust, and height (Alison et al., 2005; } \\
\text { Mondragón-Ceballos et al., 2015; Pedersen et al, 2004). } \\
\text {-Gene polymorphisms associated with regulations of fat and } \\
\text { height, with a stronger effect in women more than men (Heid et } \\
\text { al., 2010; Schuit et al., 2004). }\end{array}$ & $\begin{array}{l}\text {-Bust (Jasien'ska et al., 2004; Symons, 1979) and hip (Huseynov } \\
\text { et al., 2012) increase in size with age as women go through } \\
\text { puberty). } \\
\text {-WHR, WSR, and WBR decrease as women go through puberty } \\
\text { and increase as women age (Jasien'ska et al., 2004; Park et al., } \\
\text { 2018; Shimokata et al., 1989). }\end{array}$ \\
\hline Ultimate Questions & Function & Evolution \\
\hline $\begin{array}{l}\text {-Why are lower WHR, WSR, and } \\
\text { WBR correlated with female } \\
\text { attractiveness? } \\
\text {-When did WHR, WSR, and } \\
\text { WBR evolve during our } \\
\text { evolutionary history? }\end{array}$ & $\begin{array}{l}\text {-WHR signals reproductive age, reproductive capability, health } \\
\text { (Singh, 1993), and reproductive history (Butoskaya et al., } \\
\text { 2017). } \\
\text {-WSR reproductive age (Shimokata et al., 1989), reproductive } \\
\text { capability (Lassek \& Gaulin, 2006), and health (Ashwell et al., } \\
\text { 2012). } \\
\text {-WBR correlates with fecundity (Jasien'ska et al., 2004). }\end{array}$ & $\begin{array}{l}\text {-A large storage of body fat in women's breasts, thighs, hips, and } \\
\text { buttocks is a unique human feature among primates (Dufour \& } \\
\text { Slather, 2002; Pond, 1997). } \\
\text {-Female height could have been under positive selection in the } \\
\text { hominid lineages (Gluckman \& Hanson, 2006). } \\
\text {-The adaptation to bipedalism in human produced waist and hip } \\
\text { (Schultz, 1969). }\end{array}$ \\
\hline
\end{tabular}




\section{Limitations in Past Studies}

Although much is known about our preferences for WHR, WSR, and WBR in women (Table 1), the conclusions drawn from previous experimental studies have limited ethological and ecological validity. A majority of experimental studies were conducted within a laboratory setting with college students (e.g., Fitzgerald, Horgan, \& Himes, 2016; Furnham, Moutafi, \& Baguma, 2002; Furnham, Petrides, \& Constantinides, 2005; Henss, 2000; Puhl \& Boland, 2001; Shin, Suh, \& Jang, 2018; Singh, 1993,1995; Streeter \& McBurney, 2003). In cases where cross-cultural studies with non-university students from diverse societies (e.g., Singh et al., 2010; Marlowe et al., 2005) were conducted, the sample sizes were still relatively small. In addition, the experimental research uses carefully manipulated stimuli to emphasize causal explanations, which could produce unnatural stimuli, compromising external validity of the conclusion (Bracht \& Glass, 1968). Hence, we do not know to whether previous findings on our preferences for lower waist-to-hip ratio, waist-to-stature ratio, and waist-to-bust ratio in females can be extended to a larger population in a naturalistic condition.

Some naturalistic studies have demonstrated our preferences for certain anthropometric measures in females (e.g., lower waist-to-hip ratios) with Miss America (Singh, 1993), playboy models (Lassek \& Gaulin, 2016), adult media models (Voracek \& Fisher, 2006), and cartoon characters (Aung \& Williams, 2018; Lassek \& Gaulin, 2016). However, we do not know whether these findings can be applied to a different category of female models (e.g., plus-size models), who could vary significantly in shapes and sizes from other types of models (e.g., fashion, glamour, and playboy models).

\section{Current Study}

The overall goal of the study is to test whether anthropometric measures influence the viewers' perceived attractiveness of plus-size models in a naturalistic setting. The attractiveness of plus-size models was operationalized based on the rankings, generated from ranker.com (Lisa, 2013). As reviewed in Table 1, WHR, WSR, and WBR have been reported to be linked with female health and fertility. Thus, we hypothesized that lower WHR, WSR, and WBR would be positively correlated with higher rankings. Recent studies also reported that WSR influences our perception of attractiveness in females more than WHR (Andrew et al., 2017; Lassek \& Gaulin, 2016). Thus, we hypothesized that WSR, in comparison to WHR, is a more important factor on the rankings of plussize models. Previously, De Veirman, Cauberghe and Hudders (2017) showed that Instagram members with high numbers of followers are more likely to be likeable and popular. To rule out the possibility that higher rankings of plus-size models in our study were produced due to their popularity, we compared the popularity rankings, generated by the number of Instagram followers, to rankings recorded on ranker.com (Lisa, 2013). Lastly, we examined whether anthropometric measures, such as WHR, WSR, and WBR actually varied between plus-size models and other types of models (e.g., fashion, glamor, playboy and adult film models) reported in previous studies. 


\section{METHOD}

\section{Data Collection}

All of our data on height, bust, waist, and hip measurements of the 49 plus-size models were collected online, specifically from model agency web pages. In some cases, the biometric measures were obtained from online news stories or the models' websites. Data on bust, waist, and hip measurements were not available for four of the models in our study. Hence, we used the clothing sizes of these four models to estimate their measurements. Both data and $\mathrm{R}$ codes for the analyses were made available online (see Appendix). We then calculated composite measures of waist-to-hip ratio, waist-to-stature ratio, and waist-to-bust ratio (Table 2).

Table 2: Descriptive Statistics of Plus-size Models' Anthropometric Measures $(n=49)$

\begin{tabular}{lllll}
\hline Variables & M & Mdn & SD & Range \\
\hline Height $(\mathrm{cm})$ & 176.16 & 175.26 & 4.37 & $157.5-188$ \\
Bust $(\mathrm{cm})$ & 102.58 & 117 & 11.35 & $79-142.24$ \\
Waist (cm) & 86.73 & 84 & 11.48 & $62-127$ \\
Hip (cm) & 116.77 & 104 & 11.82 & $84-150$ \\
$\begin{array}{l}\text { Waist-to-hip } \\
\text { (WHR) }\end{array}$ & 0.74 & 0.74 & 0.06 & $0.64-0.94$ \\
$\begin{array}{l}\text { Waist-to-stature } \\
\text { ratio (WSR) }\end{array}$ & 0.49 & 0.48 & 0.07 & $0.36-0.75$ \\
$\begin{array}{l}\text { Waist-to-bust ratio } \\
\text { (WBR) }\end{array}$ & 0.85 & 0.84 & 0.09 & $0.72-1.23$ \\
\hline
\end{tabular}

Rankings of the plus-size models were obtained from (https://www.ranker.com/ list/plus-size-models/lisanelsontoton). The photographs of 49 U.S. plus-size models were listed by Lisa (2013) on the web page, which has been viewed 2.60 million times, with 146,000 votes from 189,000 site visitors. The rankings of the models were generated based on the relative number of upvotes and downvotes from site visitors. We also considered the popularity of plus-size models outside of ranker.com (Lisa, 2013). The popularity of plus-size models was operationalized based on the number of Instagram followers for each model. Out of 49 models, 47 models had Instagram accounts. The number of Instagram followers was then rank-ordered to generate the general popularity rankings of plus-size models. 


\section{Stimuli}

Although varied in postures and settings, the listed photographs of plus-size models were further coded into three body shot categories: full-body shots $(n=15)$, almost-full body shots $(n=28)$ and upper-body shots $(n=6)$. Full-body shots displayed the photographs of models from head to toe; almost-full body shots displayed the photographs of models from head to thigh; upper-body shots mostly displayed the photographs of models from head to waist. According to Lisa (2013), these listed plus-size models were currently active in the plus-size industry and could have a [US] clothing size of $6 / 8$ and up.

\section{Data Analysis}

All analyses were done in the open-source statistical software R (R Core Team, 2017). Since our dependent variables were rankings in ordinal measurement, spearman correlations were used to test the association between rankings and anthropometric measures of WHR, WSR, and WBR. To control the impact of potential confounds between variables, an ordinal logistic regression was run with all three anthropometric measures to predict rankings of plus-size models. It is possible that rankings of plus-size models were influenced by the popularity of plus-size models. To rule out the possibility, we ran a spearman correlation between rankings, obtained from ranker.com (Lisa, 2013), and popularity rankings, obtained from the number of Instagram followers for each model. Lastly, we ran several two-sided one-sample Wilcoxon Signed Rank tests to examine if WHRs, WSRs, and WBRs of plus-size models were significantly different from the mean anthropometric measures of other types of models, reported in previous studies.

\section{RESULTS}

\section{Spearman Correlations between Anthropometric Measures and Rankings}

Several Spearman's rank-order correlations were run to examine the relationship between the anthropometric measures of WHRs, WSRs, WBRs, and rankings of plus-size models (Figure 1). There were statistically significant positive correlations between lower WHRs and rankings of the model, $\mathrm{r}_{\mathrm{s}}(47)=.284, \mathrm{p}=.048$, between lower WSRs and rankings of the model, $\mathrm{r}_{\mathrm{s}}(47)=.313, \mathrm{p}=.003$, and between lower WBRs and rankings of the model, $\mathrm{r}_{\mathrm{s}}(47)=.389, \mathrm{p}=.006$.
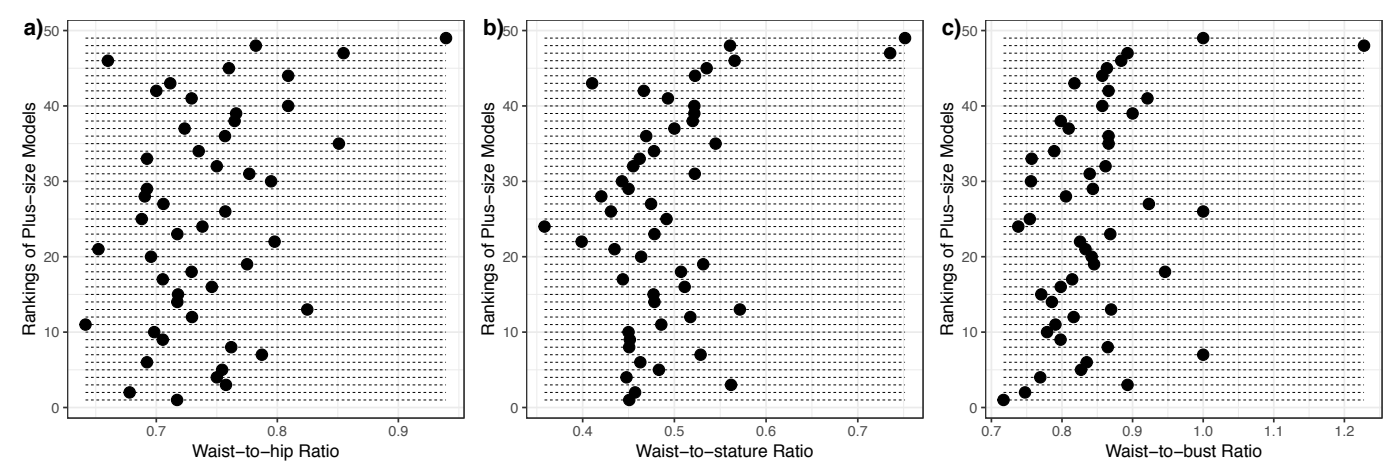

Figure 1: Dot plots showing the relationship between the rankings of plus-size models and their respective (a) waist-to-hip ratios, (b) waist-to-stature ratios, and (c) waist-to-bust ratios. The package ggplot2 (Wickham, 2016) was used to create this figure. 


\section{An Ordinal Logistic Regression between Anthropometric Measures and Rankings}

Spearman correlations between anthropometric measures were also significantly correlated (see Figure 2). To test the unique impact of our anthropometric variables on the rankings of plus-size models, an ordinal logistic regression was run using the ordinal package, in $\mathrm{R}$ (Christensen, 2018). The regression model included all three anthropometric measures as predictors and rankings as a dependent variable. The likelihood ratio test, using scale_test function in the ordinal package, revealed that the proportional odds assumption of the ordinal logistic regression was met. The tested model was a better fit than the null model, $\mathrm{X}^{2}(3)=18.78, \mathrm{p}<.001$, explaining $32 \%$ of the variance (Nagelkerke's $\left.\mathrm{R}^{2}\right)$ on the rankings. The results revealed that WSR $(\beta=10.73, \mathrm{p}$ $=.051)$ and WBR $(\beta=8.79, \mathrm{p}=.015)$ were significant predictors, but WHR $(\beta=5.39, \mathrm{p}$ $=.369)$ was not. The coefficient of WSR can be interpreted as the following. With a point increase in WSR, there was a 10.73 decrease in the expected ranking (increasing scores indicated lower rankings) of plus-size models on the log odds scale.

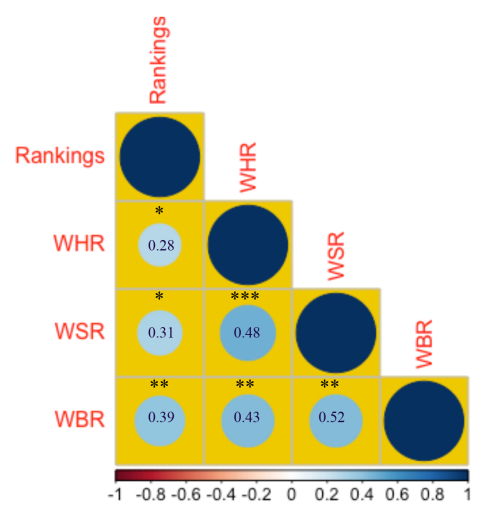

Figure 2: A correlogram displaying spearman correlation coefficients between the anthropometric measures and the rankings of plus-size models. WHR = Waist-to-hip ratio, $\mathrm{WSR}=$ Waist-to-stature ratio, and WBR = Waist-to-bust ratio. ${ }^{*} p<.05,{ }^{* *} p<.01,{ }^{* * *} p<.001$. The package corrplot (Wei \& Simko, 2017) was used to create this figure.

\section{Additional Considerations \& Analyses}

Following previous studies on anthropometric measures (e.g., Andrews et al., 2017; Lassek \& Gaulin, 2016), we ran multiple regression analysis on WHR, WSR, and WBR to predict rankings of plus-size models. However, multicollinearity between variables (see Figure 2) could complicate the interpretation of our results in our ordinal logistic regression. To partial out the correlations between WHR, WSR, and WBR, we ran the principal component analysis (PCA). Before running PCA, we first considered the possible influence of photograph presentations on the rankings. Since some photographs only displayed upper-body shots $(\mathrm{n}=6)$, WSRs were less likely to influence the viewers' ratings. Thus, we eliminated these six photographs with upper-body shots from our analysis. Second, we considered the possible influence of outliers. Since PCA can be 
influenced by outliers, we eliminated the models $(n=4)$ whose WHRs, WSRs, and WBRs were two standard deviations above or below the mean.

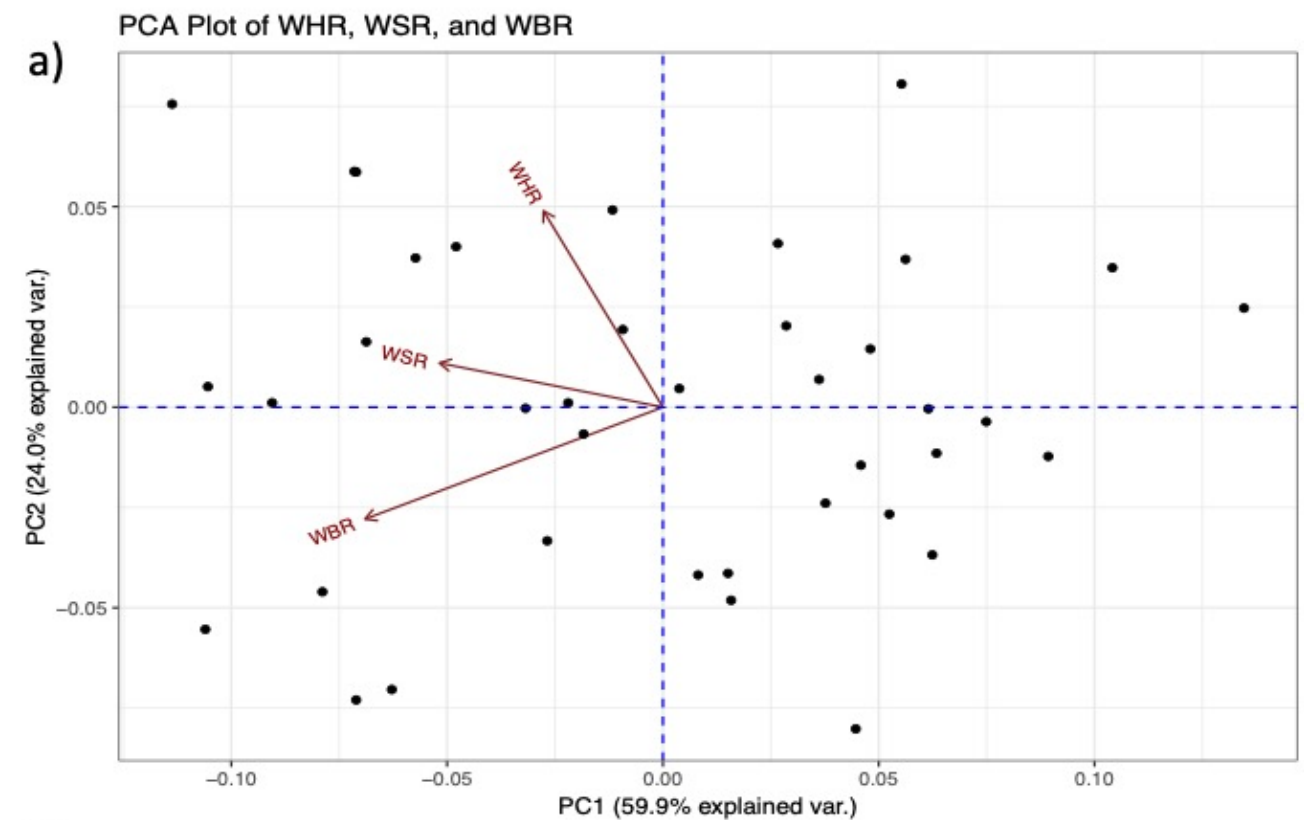

b)

\begin{tabular}{|cccc|}
\hline Variables & PC1 & PC2 & PC3 \\
\hline WHR & -0.31 & 0.85 & 0.42 \\
\hline WSR & -0.57 & 0.19 & -0.80 \\
\hline WBR & -0.76 & -0.49 & 0.43 \\
\hline SD & 0.06 & 0.04 & 0.03 \\
\hline $\begin{array}{l}\text { Variance } \\
\text { Explained }\end{array}$ & 59.95 & 24.02 & 16.03 \\
\hline
\end{tabular}

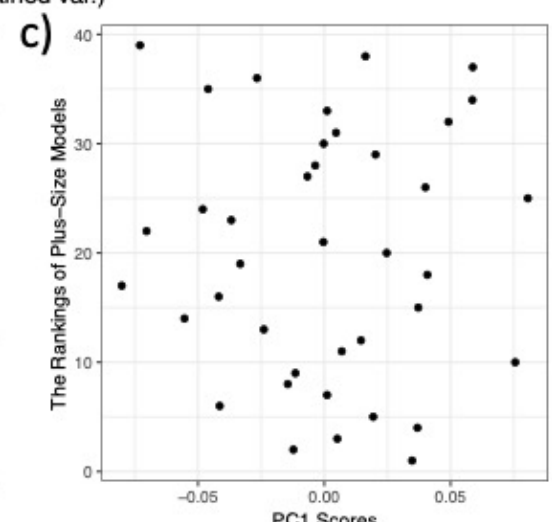

Figure 3: Results of principal component regression on rankings of plus-size models. In panel (a), principal component analysis (PCA) biplot of anthropometric measures shows the loadings of WHR, WSR, and WBR (arrows), the scores (points), the variance of each variable (the length of the arrows), and correlations (the angles between the arrows). Panel (b) displays the loadings of the variables on each axis. Panel (c) plots the significant negative correlations between PC1 scores and rankings of plussize models, obtained from ordinal regression model. WHR = Waist-to-hip ratio, WSR = Waist-to-stature ratio, and WBR = Waist-to-bust ratio. The package ggbiplot $(\mathrm{Vu}$, 2011) was used to create this figure.

With the final sample of 39 models, we performed PCA on WHR, WSR, and WBR using princomp function of the built-in $\mathrm{R}$ stats package ( $\mathrm{R}$ Core Team, 2017). The results from PCA are presented in Figure 3. All three variables: WHR, WSR, and WBR were negatively loaded on the first principal component (PC1), which explained about $60 \%$ of the variations. In the second principal component (PC2), which explained about $24 \%$ 
of the variations, WHR was positively loaded whereas WBR was negatively loaded. The third principal component (PC3) explained 16\% of the variations observed and was loaded negatively and primarily by WSR. With the ordinal package, in R (Christensen, 2018), an additional ordinal logistic regression was conducted predicting rankings of plus-size models from the three PCs derived from the PCA. The test revealed that PC1 $(\beta=-10.42, p=.004)$ was a significant predictor, but PC2 $(\beta=-0.25, p=.973)$ and PC3 $(\beta=2.42, \mathrm{p}=.790)$ were not. With a point increase in PC1 (increasing PC1 indicates lower latent values of WHR, WSR, and WBR), there is a 10.42 increase in the expected ranking (decreasing scores indicate higher rankings) of plus-size models on the log odds scale. In other words, plus-size models with lower latent body component scores of WHR, WSR, and WBR were more likely to receive higher rankings.

\section{Does Popularity Explain Rankings of Plus-size Models?}

To test whether popularity level of plus-size models explain why certain plus-size models are ranked higher on the list of ranker.com (Lisa, 2013), we ran a spearman correlation between rankings from the website and popularity rankings, generated by the number of Instagram followers for each model. No significant correlation between preference rankings and popularity rankings of the model was found, $\mathrm{r}_{\mathrm{s}}(45)=-0.09, \mathrm{p}=.538$.

\section{Plus-size Vs. Fashion, Glamor, Playboy, and Adult Film Models}

Several two-sided one-sample Wilcoxon Signed Rank tests were run to examine if the median anthropometric measures of plus-size models were significantly different from the average anthropometric measures of other types of models, reported in previous studies (Table 3). If the median values were not reported in previous studies, the mean values of anthropometric measures were used to compare the average measures between plus-size and other types of models (see Table 3). The median WHRs of plus-size models were significantly greater than the average WHRs of fashion models, glamor models, playboy models, and adult film models ( $\mathrm{p}<.001$ for all comparisons). The median WSRs of plus-size models were also significantly greater than the average WSRs of playboy models and adult film models $(\mathrm{p}<.001)$. No comparison on the WSRs between plus-size models vs. fashion models or glamor models were made since the average values were not available. The median WBRs of plus-size models were also significantly greater than the average WBRs of fashion models, glamor models, playboy models, and adult film models ( $\mathrm{p}<.001$ for all comparisons). 
Table 3: The Average Anthropometric Measures of Models and College Women in Current and Previous Studies.

\begin{tabular}{llccc}
\hline Models & Studies & WHR & WSR & WBR \\
\hline Plus-size Models $(n=49)$ & Current study & 0.74 & 0.49 & 0.85 \\
Fashion Models $(n=300)$ & Tovée et al., 1997 & 0.71 & - & 0.72 \\
Glamour Models $(n=300)$ & Tovée et al., 1997 & 0.68 & - & 0.66 \\
Adult Film Models $(n=125)$ & Voracek \& Fisher, 2006 & 0.67 & 0.37 & 0.69 \\
Playboy Models $(n=673)$ & Lassek \& Gaulin, 2016 & 0.68 & 0.36 & 0.67 \\
\hline
\end{tabular}

Note. One-sample Wilcoxon Signed Rank Tests revealed the median anthropometric measures of the plus-size models were all significantly greater from the average anthropometric measures of fashion models, glamor models, adult film models, and playboy models. The data reported for current study and (Voracek \& Fisher, 2006) represent the median values whereas the data reported in other studies represent mean values. _= unavailable information, WHR $=$ Waist-to-hip ratio, $W S R=$ Waist-to-stature ratio, and WBR $=$ Waist-to-bust ratio.

\section{DISCUSSION}

Our study is the first to test whether plus-size models' waist-to-hip ratio (WHR), waistto-stature ratio (WSR), and waist-to-bust ratio (WBR) influence the perceptions of attractiveness in a naturalistic setting. The results revealed that the models with lower WHRs, WSRs, and WBRs, also received higher rankings (Figure 1). These findings are consistent with previously studies that female physical attractiveness is strongly related to WHR (Lassek \& Gaulin, 2016; Singh, 1993; Furnham et al., 2002; Furnham et al., 2005), WSR (Andrews et al., 2017; Lassek \& Gaulin, 2016), and WBR (Crossley Cornelissen, \& Tovée, 2012; Gründl, Eisenmann-Klein, \& Prantl, 2009; Lassek \& Gaulin, 2016). Previously, some studies have also argued that a lower BMI is more strongly correlated with female attractiveness more than a lower WHR (Tovée et al., 1998; Tovée et al., 1999; Tovée et al., 2002). In one study, the overweight female figure with a higher WHR of 0.86 was judged to be more attractive than the figure with a lower WHR of 0.72 , suggesting that WHR is of less importance in heavier women (Puhl \& Boland, 2010). In contrast with previous findings, the current finding that WHR is strongly correlated with rankings of plus-size models suggests WHR is an influential determinant of physical attractiveness, even in heavier women.

In a subsequent regression analysis, where the models' WHR, WSR, and WBR are simultaneously controlled, WHR is a weaker predictor of rankings than WSR and WBR. This finding on WSR corroborates with recent findings that WSR is a stronger determinant of female physical attractiveness than WHR (Andrews et al., 2017; Lassek \& Gaulin, 2016). The replication that WSR is a more important factor than WHR in our study also supports the previous argument that WSR explains the attractiveness variance accounted by WHR (Lassek \& Gaulin, 2016). In addition, our finding that WBR 
explains rankings of our plus-size models strengthens the hypothesis that the larger breasts and narrow waists in women indicate high reproductive potential in women. Jasien'ska et al. (2004) previously reported that the lower WBR correspond to the higher concentration of estradiol level in women, which is linked with the increased probability of conception. Hence, a lower WBR in plus-size models would be attractive to male viewers and ideal for female viewers. Our findings on the relationship between anthropometric measures and rankings of plus-size models cannot be explained by their popularity. The popularity ranking, based on the number of Instagram followers, does not correlate with the recorded rankings of plus-size models on ranker.com (Lisa, 2013).

As expected, the average WHR, WSR, and WBR of plus-size models were much greater than the average ratio of fashion, glamor, playboy, and adult film models. Yet, our study found that both WSR and WBR serve as unique predictors of rankings of plus-size models. These findings suggest that a smaller waist circumference is an important cue for the judgement of female physical attractiveness, even in plus-size models. Heavier women tend to have larger bust sizes; however, women who were rated higher on attractiveness tend to have both smaller waist sizes and larger bust sizes (Lassek \& Gaulin, 2016). Andrews et al. (2017) found that WSR is associated with estimated age and parity (i.e. the number of children a woman had given birth to). As reviewed in Table 1 , we also argued that a lower WSR would serve as cues for both sexual maturity and a low parity, with a high potential to birth to a large-brain infant. Future studies should investigate whether WSR actually correlates with higher levels of female reproductive hormones and fertility.

Future studies should also examine the integrated impact of anthropometric measures on attractiveness. Given their high correlations, we can theoretically dissociate the influence of WHR, WSR, and WBR on attractiveness. In our multiple regression model with three anthropometric measures, WSR and WBR served as unique predictors. In a study by Lassek and Gaulin (2016), a multiple regression model with four different anthropometric measures yielded no significant results. In both of these studies and others, multi-collinearity could complicate the validity of the models due to high correlations between predictor variables. In our study, we further conducted PCA on anthropometric measures to decompose the correlated predictors into uncorrelated measures. Our results indicate that plus-size models with lower latent body component of WHR, WSR, and WBR (PC1) also received higher rankings. However, latent body components upon which WHR was heavily loaded (PC2) and WSR was heavily loaded (PC3) did not predict rankings of plus-size models. These findings suggest that WHR, WSR, and WBR are necessary, but not sufficient determinants of body attractiveness, at least among plus-size models. Future studies should investigate which unique combinations of anthropometric measures are most critical in determining female body attractiveness. Given the importance of lower WHR on attractiveness in literature, future studies should examine whether WSRs and WBRs become more important visual cues when the homogeneity of WHRs is present. The findings in our study also reveal that the anthropometric measures explain the variation of rankings observed among plus-size models, with unstandardized stimuli. Future studies can closely examine whether people can reliably estimate the anthropometric measures of individuals and to what extent these measures influence attractiveness in the midst of variations in clothing, movements, and postures. 


\section{Limitations}

Our study has several limitations. First, the influence of WHR, WSR, and WBR on rankings was tested with plus-size models, some of whom might be considered as obese. Some studies, for example, have argued that the investigation of WHR on female attractiveness from evolutionary framework should be evaluated within an ancestrally valid range of body weight (Furnham et al., 2002). Obesity does not apply as an ancestrally valid category of body weight since resources were never in surplus (Cloud \& Perilloux, 2014). Nevertheless, our study yields insights into the influence of WHR, WSR, and WBRs on female attractiveness in the modern world. For example, in the U.S., two-thirds of women are considered overweight or obese (Flegal, Carroll, Ogden, \& Curtin, 2010), and the women's plus-size clothing category has become a growing market (Alexander, Pisut \& Ivanescu, 2011). Second, the stimuli in our study were not standardized, unlike in previous experimental studies. For examples, the models in our photograph vary in term of their postures and facial attractiveness. Nevertheless, these variations in posture apply to all stimuli and would not bias the results heavily. In addition, Shin et al. (2018) reported that the facial attractiveness ratings are strongly correlated with WHR in women; hence, the variations in facial attractiveness of plus-size models are also less likely to explain our results. In our principal component regression where potential outliers and photographs with upper-body shots were removed, the latent body component of WHR, WSR, and WBR still predicted rankings of plus-size models. Nevertheless, the rankings could be still be influenced by other external factors, not considered in our analysis. Third, we do not know the demographic characteristics of participants who voted on the photographs. Nevertheless, our analyses were based a large sample of votes from 189,000 site visitors, yielding significant insights from a representative sample of the U.S. population. Last but not least, the actual selection of plus-size models was based on one person's choices. To the extent that this choice is an unbiased selection of plus-size models is debatable and unknown.

\section{Conclusions}

In a naturalistic condition, we found that plus-size models' waist-to-hip ratio (WHR), waist-to-stature ratio (WSR), and waist-to-bust ratio (WBR) predicted rankings from viewers, such that those with lower WHR, WSR, and WBR received higher rankings. The popularity of plus-size models was not a significant factor in explaining high rankings. We also found that the average WHR, WSR, and WBR of plus-size models were greater than those of fashion, glamor, playboy, and adult film models. Yet, WSR and WBR of plus-size models served as unique predictors of rankings from viewers, suggesting that smaller waist sizes and bigger breasts are important cues of female attractiveness regardless of body weight. 


\section{REFERENCES}

Alexander, M., Pisut, G. R., \& Ivanescu, A. (2012). Investigating women's plus-size body measurements and hip shape variation based on size USA data. International Journal of Fashion Design, Technology and Education, 5(1), 3-12. DOI

Andrews, T. M., Lukaszewski, A. W., Simmons, Z. L., \& Bleske-Rechek, A. (2017). Cue-based estimates of reproductive value explain women's body attractiveness. Evolution and Human Behavior, 38(4), 461-467. DOI

Aung, T., \& Williams, L. (2018). Mirror, mirror on the wall: Whose figure is the fairest of them all? Evolutionary Behavioral Sciences. DOI

Bracht, G. H., \& Glass, G. V. (1968). The external validity of experiments. American Educational Research Journal, 5(4), 437-474. DOI

Buss, D. M. (1989). Sex differences in human mate preferences: Evolutionary hypotheses tested in 37 cultures. Behavioral and Brain Sciences, 12(01), 1. DOI

Butovskaya, M., Sorokowska, A., Karwowski, M., Sabiniewicz, A., Fedenok, J., Dronova, D., ... Sorokowski, P. (2017). Waist-to-hip ratio, body-mass index, age and number of children in seven traditional societies. Scientific Reports, 7(1). DOI

Christensen, R. H. B. (2018). Ordinal - Regression models for ordinal data. R package version 2018.8-25. http://www.cran.r-project.org/package $=$ ordinal/

Cloud, J. M., \& Perilloux, C. (2014). Bodily attractiveness as a window to women's fertility and reproductive value. In V. A. Weekes- Shackelford \& T. K. Shackelford (Eds.),

Evolutionary perspectives on human sexual psychology and behavior (pp. 135-152). New York: Springer. $\underline{\mathrm{DOI}}$

Cornelissen, P. L., Hancock, P. J. B., Kiviniemi, V., George, H. R., \& Tovée, M. J. (2009). Patterns of eye movements when male and female observers judge female attractiveness, body fat and waist-to-hip ratio. Evolution and Human Behavior, 30(6), 417-428. DOI

Cosmides, L., \& Tooby, J. (1995). From evolution to adaptations to behavior: Toward an integrated evolutionary psychology. In R. Wong (Ed.), Biological perspectives on motivated activities (pp. 11-74). NJ: Ablex: Norwood.

Crossley, K., Cornelissen, P., \& Tovee, M. (2012). What is an attractive body? using an interactive $3 \mathrm{D}$ program to create the ideal body for you and your partner. Plos One, 7(11), e50601. DOI

De Veirman, M., Cauberghe, V., \& Hudders, L. (2017). Marketing through instagram influencers: The impact of number of followers and product divergence on brand attitude. International Journal of Advertising, 36(5), 798-828. DOI

Dufour, D. L., \& Slather, M. L., (2002). Comparative and evolutionary dimensions of the energetics of human pregnancy and lactation. American Journal of Human Biology, 14(5), 584-602. DOI

Ellison, P. T. (2009). On fertile ground: A natural history of human reproduction. Cambridge: Harvard University Press.

Fisher, M. L., \& Voracek, M. (2006). The shape of beauty: determinants of female physical attractiveness. Journal of Cosmetic Dermatology, 5(2), 190-194. DOI

Fitzgerald, C. J., Horgan, T. G., \& Himes, S. M. (2016). Shaping men's memory: The effects of a female's waist-to-hip ratio on men's memory for her appearance and biographical information. Evolution and Human Behavior, 37(6), 510-516. DOI

Flegal, K. M., Carroll, M. D., Ogden, C. L., \& Curtin, L. R. (2010). Prevalence and trends in obesity among US adults, 1999-2008. JAMA: The Journal of the American Medical Association, 303(3), 235-241. DOI 
Furnham, A., Moutafi, J., \& Baguma, P. (2002). A cross-cultural study on the role of weight and waist-to-hip ratio on female attractiveness. Personality and Individual Differences, 32(4), 729-745. DOI

Furnham, A., Petrides, K. V., \& Constantinides, A. (2005). The effects of body mass index and waist-to-hip ratio on ratings of female attractiveness, fecundity, and health. Personality and Individual Differences, 38(8), 1823-1834. DOI

Gangestad, S. W., \& Buss, D. M. (1993). Pathogen prevalence and human mate preferences. Ethology and Sociobiology, 14(2), 89-96. DOI

Gluckman, P. D., \& Hanson, M. A. (2006). Evolution, development and timing of puberty. Trends in Endocrinology \& Metabolism, 17(1), 7-12. DOI

Gründl, M., Eisenmann-Klein, M., \& Prantl, L. (2009). Quantifying female bodily attractiveness by a statistical analysis of body measurements. Plastic and Reconstructive Surgery, 123, 1064-1071. DOI

Huseynov, A., Zollikofer, C. P., Coudyzer, W., Gascho, D., Kellenberger, C., Hinzpeter, R., \& Ponce de León, M. S. (2016). Developmental evidence for obstetric adaptation of the human female pelvis. Proceedings of the National Academy of Sciences of the United States of America, 113(19), 5227. DOI

Jasien'ska, G., Ziomkiewicz, A., Ellison, P. T., Lipson, S. F., \& Thune, I. (2004). Large breasts and narrow waists indicate high reproductive potential in women. Proceedings of the Royal Society B: Biological Sciences, 271(1545), 1213-1217. DOI

Kościński, K. (2014). Assessment of Waist-to-Hip Ratio Attractiveness in Women: An Anthropometric Analysis of Digital Silhouettes. Archives of Sexual Behavior, 43(5), 989997. DOI

Lassek, W. D., \& Gaulin, S. J. C. (2006). Changes in body fat distribution in relation to parity in American women: A covert form of maternal depletion. American Journal of Physical Anthropology, 131(2), 295-302. DOI

Lassek, W. D., \& Gaulin, S. J. C. (2016). What Makes Jessica Rabbit Sexy? Contrasting Roles of Waist and Hip Size. Evolutionary Psychology, 14(2), 147470491664345. DOI

Lewis, D. M. G., Al-Shawaf, L., Conroy-Beam, D., Asao, K., \& Buss, D. M. (2017). Evolutionary psychology: A how-to guide. American Psychologist, 72(4), 353-373. DOI

Lisa, T. (2013, February 19). Jaw-droppingly gorgeous plus size models. Retrieved from Ranker.com: https://www.ranker.com/list/plus-size-models/lisanelsontoton

Heid, I. M., Jackson, A. U., Randall, J. C., Winkler, T. W., Qi, L., ... Lindgren, C. M. (2010). Meta-analysis identifies 13 new loci associated with waist-hip ratio and reveals sexual dimorphism in the genetic basis of fat distribution. Nature Genetics, 42(11), 949-960. $\underline{\text { DOI }}$

Henss, R. (2000). Waist-to-hip ratio and female attractiveness. evidence from photographic stimuli and methodological considerations. Personality and Individual Differences, 28(3), 501-513. DOI

Marlowe, F., Apicella, C., \& Reed, D. (2005). Men's preferences for women's profile waist-to-hip ratio in two societies. Evolution and Human Behavior, 26(6), 458-468. DOI

Mondragón-Ceballos, R., García Granados, M. D., Cerda-Molina, A. L., Chavira-Ramírez, R., \& Hernández-López, L. E. (2015). Waist-to-Hip Ratio, but not body mass Index, is associated with testosterone and estradiol concentrations in young women. International Journal of Endocrinology, 2015, 1-6. DOI

Pedersen, S. B., Kristensen, K., Hermann, P. A., Katzenellenbogen, J. A., \& Richelsen, B. (2004). Estrogen Controls Lipolysis by Up-Regulating a2A-Adrenergic Receptors Directly in Human Adipose Tissue through the Estrogen Receptor $\alpha$. Implications for the Female 
Fat Distribution. The Journal of Clinical Endocrinology \& Metabolism, 89(4), 1869-1878. $\underline{\mathrm{DOI}}$

Pond C. (1997). The biological origins of adipose tissue in humans. In M. E. Morbeck, A. Galloway, A.L. Zihlman (Eds.), The evolving female: A life history perspective (pp. 147162). Princeton: Princeton University Press. DOI

Puhl, R. M., \& Boland, F. J. (2001). Predicting female physical attractiveness: Waist-to-hip ratio versus thinness. Psychology, Evolution \& Gender, 3(1), 27-46. DOI

Park, H.J., Hong, Y. H., Cho, Y. J., Lee, J. E., Yun, J. M., Kwon, H., \& Kim, S. H. (2018). Trends and cut-point changes in obesity parameters by age groups. Journal of Korean Medical Science, 33(7): e47. DOI

R Core Team (2017). R: A language and environment for statistical computing. R Foundation for Statistical Computing, Vienna, Austria.

Rhodes, G. (2006). The Evolutionary Psychology of Facial Beauty. Annual Review of Psychology, 57(1), 199-226. DOI

Schuit, S. C. E., van Meurs, J. B. J., Bergink, A. P., van der Klift, M., Fang, Y., Leusink, G., ... Pols, H. A. P. (2004). Height in pre- and postmenopausal women is influenced by estrogen receptor a gene polymorphisms. The Journal of Clinical Endocrinology \& Metabolism, 89(1), 303-309. DOI

Schultz, A. H. (1969). The life of primates. New York: University Books.

Shimokata, H.; Andres, R.; Coon, P. J.; Elahi, D.; Muller, D. C.; Tobin, J. D. (1989). Studies in the distribution of body fat. II. Longitudinal effects of change in weight. International Journal of Obesity, 13(4), 455-464.

Shin, J., Suh, E. M., \& Jang, D. (2018). Mate value at a glance: Facial attractiveness reveals women's waist-to-hip ratio and men's household income. Personality and Individual Differences, 135, 128-130. DOI

Singh, D. (1993.). Adaptive significance of female physical attractiveness: Role of waist-to-hip ratio. Journal of Personality and Social Psychology, 65(2): 293-307. DOI

Singh, D., Dixson, B. J., Jessop, T. S., Morgan, B., \& Dixson, A. F. (2010). Cross-cultural consensus for waist-hip ratio and women's attractiveness. Evolution and Human Behavior, 31(3), 176-181. DOI

Streeter, S., \& McBurney, D. (2003). Waist-hip ratio and attractiveness - new evidence and a critique of "a critical test". Evolution and Human Behavior, 24(2), 88-98. DOI

Symons, D. (1979). The Evolution of Human Sexuality. New York: Oxford University Press.

Tinbergen, N. (1963). On the aims and methods of ethology. Zeitschrift für Tierpsychologie, 20(4), 410-33. DOI

Tovée, M., \& Cornelissen, P. (2001). Female and male perceptions of female physical attractiveness in front-view and profile. British Journal of Psychology, 92(2), 391-402. $\underline{\mathrm{DOI}}$

Tovée, M. J., Hancock, P. J. B., Mahmoodi, S., Singleton, B. R. R., \& Cornelissen, P. L. (2002). Human female attractiveness: waveform analysis of body shape. Proceedings of the Royal Society B: Biological Sciences, 269(1506), 2205-2213. DOI

Tovée, M. J., Maisey, D. S., Emery, J. L., \& Cornelissen, P. L. (1999). Visual cues to female physical attractiveness. Proceedings of the Royal Society B: Biological Sciences, 266(1415), 211-218. DOI

Tovée, M., Reinhardt, S., Emery, J., \& Cornelissen, P. (1998). Optimum body-mass index and maximum sexual attractiveness. The Lancet, 352(9127), 548. DOI

Voracek, M., \& Fisher, M. L. (2006). Success Is All in the Measures: Androgenousness, Curvaceousness, and Starring Frequencies in Adult Media Actresses. Archives of Sexual Behavior, 35(3), 297-304. DOI 
Venn, A., Bruinsma, F., Werther, G., Pyett, P., Baird, D., Jones, P., Rayner, J., \& Lumley, J. (2005). Estrogen treatment to reduce the adult height of tall girls: Long-term effects on fertility. Obstetrical \& Gynecological Survey, 60(5), 306-307. DOI

Vincent $\mathrm{Q}$. Vu (2011). ggbiplot: A ggplot2 based biplot. R package version 0.55. http:// github.com/vqv/ggbiplot

Wei, T., \& Simko, V. (2017). R package "corrplot": Visualization of a Correlation Matrix. R package version 0.84. Available from https://github.com/taiyun/corrplot

Wickham, H. (2016). Ggplot2: Elegant graphics for data analysis. New York, NY: Springer-Verlag New York.

Wittman, A. B., \& Wall, L. L. (2007). The evolutionary origins of obstructed labor: Bipedalism, encephalization, and the human obstetric dilemma. Obstetrical \& Gynecological Survey, 62(11), 739-748. DOI

\section{APPENDIX}

Data and $\mathrm{R}$ codes for analyses are publicly made available online. They can be obtained from

https://osf.io/dt8rp/?view_only=afc9425bbe6743ae9c7b599fe705e95b 